\title{
Alterations in proteins of bone marrow extracellular matrix in undernourished mice
}

C.L. Vituri ${ }^{1}$, M. Alvarez-Silva², A.G. Trentin ${ }^{2}$ and P. Borelli ${ }^{3}$

\author{
Departamentos de AAnálises Clínicas, Centro de Ciências da Saúde and \\ ${ }^{2}$ Biologia Celular, Embriologia e Genética, Centro de Ciências Biológicas, \\ Universidade Federal de Santa Catarina, Florianópolis, SC, Brasil \\ ${ }^{3}$ Departamento de Análises Clínicas e Toxicológicas, \\ Faculdade de Ciências Farmacêuticas, U niversidade de São Paulo, \\ São Paulo, SP, Brasil
}

\author{
Correspondence \\ M. Alvarez-Silva \\ Divisão de Biologia Celular \\ Centro de Ciências Biológicas, UFSC \\ 88040-900 Florianópolis, SC \\ Brasil \\ Fax: + 55-48-331-9672 \\ E-mail: malvarez@ccb.ufsc.br \\ Presented at the 5th Brazilian \\ Symposium on Extracellular \\ Matrix - SIMEC, Angra dos Reis, \\ RJ, Brasil, September 7-10, 1998. \\ Research supported by CNPq, \\ FU NPESQ UISA 97, CAPES and \\ FAPESP (No. 13347-4/97).
}

Received January 22, 1999 Accepted April 10, 2000

\section{Abstract}

The objective of the present study was to determine the effect of protein malnutrition on the glycoprotein content of bone marrow extracellular matrix (ECM). Two-month-old male Swiss mice were submitted to protein malnutrition with a low-protein diet containing $4 \%$ casein as compared to $20 \%$ casein in the control diet. When the experimental group had attained a $20 \%$ loss of their original body weight, we extracted the ECM proteins from bone marrow with PBS buffer, and analyzed ECM samples by SDS-PAGE (7.5\%) and ECL Western blotting. Quantitative differences were observed between control and experimental groups. Bone marrow ECM from undernourished mice had greater amounts of extractable fibronectin (1.6fold increase) and laminin (4.8-fold increase) when compared to the control group. These results suggest an association between fluctuations in the composition of the hematopoietic microenvironment and altered hematopoiesis observed in undernourished mice.

\section{Introduction}

Protein-calorie malnutrition decreases blood cell production and interferes with both innate and adaptive immunity, as it affects both phagocytosis and the immune response (1-3). Blood cells arise in the bone marrow from stem cells able to undergo processes of proliferation and differentiation in the hematopoietic microenvironment. The bone marrow microenvironment is highly organized and regulates the location and physiology of the stem cells as well as the production and release of leukocytes and erythro-

\section{Key words}

- Fibronectin

- Bone marrow

- Extracellular matrix

- Malnutrition cytes from bone marrow to peripheral blood. The hematopoietic microenvironment is composed of stromal cells (fibroblasts, macrophages, endothelial cells, adipocytes), accessory cells ( $\mathrm{T}$ lymphocytes, monocytes), and their products (extracellular matrix (ECM) proteins and cytokines), which influence the self-renewal, proliferation and differentiation of hematopoietic stem and progenitor cells (4).

The ECM has been shown to be involved not only as a physical support for the hematopoietic elements, but also in different biological functions such as cell adhesion 
and de-adhesion, binding and presentation of various cytokines, as well as regulation of cell growth $(5,6)$.

Fibronectin is a ubiquitous molecule, consisting of two similar subunits joined by disulfide bonds, and can be synthesized by bone marrow stromal cells. Due to alternative splicing this matrix component exists in a variety of isoforms (7). Fibronectin is present in soluble form in plasma, and in insoluble form both in the ECM of connective tissue-forming cells and in basement membranes (8). Fibronectin is involved in the adhesion and maturation of the erythrocyte lineage (5). Adhesion of multipotent hematopoietic progenitor cells to fibronectin via the $\alpha 5 \beta 1$ integrin may control the growth of hematopoietic cells, inhibiting apoptosis of primitive cells (9) or negatively controlling hematopoiesis. Negative control of hematopoiesis may inhibit cytokine-induced proliferation of myeloid cell lineages (5).

Laminins are also important glycoproteins from the bone marrow ECM. Laminins are heterotrimeric glycoproteins. Laminin1 , the prototype of the laminin family, originally purified from the murine EngelbrethHolm-Swarm (EHS) tumor, consists of three polypeptide chains, $\alpha 1$ (400 kDa), $\beta 1$ (200 $\mathrm{kDa})$ and $\gamma 1(200 \mathrm{kDa})$. A variety of biological activities has been ascribed to laminin. These activities include interaction with type IV collagen, entactin, and heparan sulfate proteoglycan, binding to cells and regulation of their development and differentiation $(5,10)$.

In a previous report we observed lymphohematopoietic modifications, such as bone marrow myeloid hypoplasia in experimental models of malnutrition (11). The objective of the present study was to evaluate the effects of protein malnutrition on the glycoprotein components of the ECM in bone marrow, focusing on fibronectin and laminin accumulation. The experimental model consisted of mice submitted to a low-protein diet. We observed many alterations in elec- trophoretic profile of ECM proteins, with accumulation of fibronectin and laminin in undernourished mice compared to controls. These data suggest that profound changes in the bone marrow microenvironment leading to changes in hematopoiesis occur in undernourished mice.

\section{Material and Methods}

\section{Experimental diet}

Two-month-old male Swiss mice obtained from Universidade Federal de Santa Catarina were housed in individual metabolic cages. The undernourished group received a diet containing $4 \%$ casein (low-protein diet) and the control group received $20 \%$ casein (control diet) for 15 days. The diet contained fibers, saline and balanced vitamin mixtures, supplemented with $0.2 \%$ choline and $0.15 \%$ methionine (11). The two groups were maintained on a light/dark cycle of $12 \mathrm{~h}$, with water and food supplied ad libitum. Body weight was monitored every $48 \mathrm{~h}$ and the animals were submitted to experimental assays when the undernourished group attained a $20 \%$ loss of their original body weight. The differences between control and undernourished mice were analyzed by the unpaired Student $t$-test.

\section{Extracellular matrix protein extraction}

Bone marrow ECM was obtained from the femurs of the mice as described by Peters et al. (12). Marrow was aspirated into PBS (80 mM NaH${ }_{2} \mathrm{PO}_{4}, 20 \mathrm{mM} \mathrm{Na} \mathrm{HPO}_{4}, 100$ $\mathrm{mM} \mathrm{NaCl}$ ), $\mathrm{pH} 7.3$, containing $2 \mathrm{mM}$ dithiothreitol, $100 \mathrm{mM} 6$-aminohexanoic acid, $1 \mathrm{mM}$ benzamidine- $\mathrm{HCl}$, and $1 \mathrm{mM}$ phenylmethylsulfonyl fluoride (all from Sigma Chemical Co., St. Louis, MO, USA) at $4^{\circ} \mathrm{C}$ and allowed to stand for $30 \mathrm{~min}$. The samples were then pooled and centrifuged at $2,500 \mathrm{~g}$ for $15 \mathrm{~min}$, and the ECM/soluble proteincontaining supernatant was recovered. 


\section{Dialysis and protein determination}

The ECM proteins from bone marrow were dialyzed exhaustively (cut-off $12 \mathrm{kDa}$; Gibco BRL, Grand Island, NY, USA) for 48 $h$ against distilled water. The protein concentration recovered after dialysis was determined using the method of Bradford (13). Bovine serum albumin was used as standard. The ECM extracts from bone marrow were pooled and maintained at $-20^{\circ} \mathrm{C}$.

\section{Polyacrylamide gel electrophoresis}

Denaturing SDS-polyacrylamide gel electrophoresis (SDS-PAGE) was performed on a $4 \%$ stacking gel and a $7 \%$ separating acrylamide gel according to the discontinuous system of Laemmli (14) under reducing conditions ( $2 \mathrm{mM}$ dithiothreitol added to the sample buffer). Gels were stained with $0.2 \%$ Coomassie blue R-250 (Sigma), 50\% methanol and $10 \%$ acetic acid and destained overnight in 50\% methanol and $10 \%$ acetic acid. Apparent molecular mass was determined using calibration kits (Pharmacia Biotech, São Paulo, SP, Brazil). The wells were loaded with $45 \mu \mathrm{g}$ of protein obtained from bone marrow ECM.

\section{Western blotting}

Electrophoretic transfer of proteins from SDS-PAGE gels to nitrocellulose membranes was performed with a mini-V8 system, according to manufacturer instructions (Gibco BRL). Transfer was performed with $45 \mu \mathrm{g}$ of protein/well run on an SDS-PAGE slab. The molecular mass calibration kit used for blotting was BenchMark Prestained Protein Ladder (Gibco BRL). The nitrocellulose membrane was removed and incubated for $1 \mathrm{~h}$ at room temperature in 5\% dry skim milk in PBS, $\mathrm{pH}$ 7.5. The following primary antibodies were used: rabbit anti-human fibronectin(A0245; Dako, Carpinteria, CA, USA) or rabbit anti-human laminin (a gift from Dr.
V. Moura Neto, Departamento de Anatomia, UFRJ). Biotinylated anti-rabbit IgG (B-7389; Sigma) and streptavidin-horseradish peroxidase (E-2886; Sigma) were incubated at room temperature for $1 \mathrm{~h}$. Immunodetection was performed by the luminescence method (ECL, Amersham Life Science, Amersham, Buckinghamshire, UK). The reagents were incubated for $1 \mathrm{~min}$ on the nitrocellulose membrane, which was then exposed to an XOmat film (Sigma) for $30 \mathrm{~s}$. Alternatively the membranes were rinsed with PBS and reacted with DAB (Sigma).

\section{Densitometric analysis}

Densitometric analysis was performed with scanned images of SDS-PAGE gels or with X-ray films from Western blot using a Microsoft Photo Editor Scanner. Alternatively, we scanned the membranes reacted with DAB. Images were analyzed and band area was determined using the Scion Image program of the National Institutes of Health, modified for Windows. We constructed linear standard curves with 0.5-5 $\mu \mathrm{g}$ of albumin (fraction V, purchased from Sigma), fibronectin $(1.5 \mu \mathrm{g}$, purchased from Gibco) and laminin ( $1 \mu \mathrm{g}$, purchased from Gibco) and the protein concentration obtained by densitometric analysis was calculated using the GraphPad Prism program, with 95\% confidence intervals.

\section{Results}

Mice treated with the low-protein diet displayed a reduction in body weight (about $24 \%$ ), while mice treated with the control diet displayed a small reduction in body weight of about $5 \%$ (Table 1).

ECM samples obtained from femoral bone marrow of undernourished and control mice were analyzed by $7.5 \%$ SDS-PAGE under reducing conditions (Figure 1). The profiles of ECM proteins were similar in both groups, but some quantitative differ- 
ences were detected when we compared ECM proteins from control and undernourished mice. In the control group, some ECM proteins were less abundant than in the undernourished group. Since the amount of protein loaded onto the SDS-PAGE wells was the same, i.e., $45 \mu \mathrm{g}$ of protein per lane, the intensity of the bands reflected the amount of proteins obtained for each experimental group. We performed densitometric analysis of the lanes and the area of the bands is shown in Table 2. Protein bands with molecular mass ranging from 60 to $76 \mathrm{kDa}$ were observed in samples from undernourished mice but were absent in control samples (Table 2). Conversely, protein bands of 123 and $49 \mathrm{kDa}$ were observed in control samples

Table 1 - Effects of the low-protein and control diet on mouse body weight.

Experimental mice were treated with a low-protein and a control diet as described in Material and Methods. Body weight was monitored every 48 h. The results are reported as percent (mean \pm SD) weight loss after 15 days of treatment. The differences in body weight at the end of treatment among the experimental groups were significant $(P<0.0001)$.

Treatment No. of animals Weight loss (\%)

\begin{tabular}{llr}
\hline Low-protein diet & 23 & $24.1 \pm 6.6$ \\
Control diet & 19 & $4.9 \pm 5.6$
\end{tabular}

Figure 1 - SDS-PAGE profile of ECM proteins obtained from control $(C)$ and undernourished (U) mice. Each SDS-PAGE lane was loaded with $45 \mu \mathrm{g}$ of protein obtained from bone marrow ECM (control or undernourished). After running, the bands were stained and measured and molecular mass determined. We observed differences in both groups. A similar profile was obtained in five different experiments done with the same ECM pool (control and undernourished). We tested three different groups of control and undernourished mice with similar results. SD, Standard molecular mass.
(Table 2), and were absent in undernourished mice. Quantitative differences were observed for the similar bands with molecular mass of 240, 220, 182, 150, 144, 127, $108,85,72,56$ and $46 \mathrm{kDa}$ from both groups.

Western blots for fibronectin obtained from mouse bone marrow ECM are depicted in Figure 2A. We observed differences in fibronectin expression in control and undernourished samples, as demonstrated by densitometry. Measurement of the fibronectin Western blot demonstrated that the amount of fibronectin was $0.63 \mu \mathrm{g}$ in the undernourished sample and $0.39 \mu \mathrm{g}$ in the control sample ( $95 \%$ confidence interval). The undernourished group showed higher expression of fibronectin compared to control groups, with a larger peak area also demonstrated by densitometry (Figure 2B).

As observed for fibronectin, expression of laminin was modified in undernourished mice (Figure 3A and B). Measurement of laminin blots demonstrated that the amount of laminin was $2.44 \mu \mathrm{g}$ in the undernourished mouse sample and $0.51 \mu \mathrm{g}$ in control samples ( $95 \%$ confidence interval).

\section{Discussion}

The main finding of this study is that protein malnutrition induced an increase in the amount of extractable fibronectin and laminin from bone marrow ECM. It is not clear whether this increase is due to an increase in laminin and fibronectin synthesis rate or to an altered pattern of deposition of these molecules in the supramolecular structure of the matrix. Regardless of the mechanism involved, it is clear that qualitative differences in bone marrow ECM composition and/or organization followed malnutrition.

Protein malnutrition modifies both specific and nonspecific resistance of organisms to infectious agents and impaired hematopoiesis and/or lymphopoiesis follows modifications in cellularity and structure of hemato- and lymphopoietic tissues $(1,15)$. 
The precise mechanisms underlying these effects are not clear. It was demonstrated that the mobilization and production of myeloid cells during inflammatory reactions in mice are affected in protein malnutrition (11). The complete maturation and release of myeloid cell lineages is delayed due to specific modifications of the stimulatory factors that control proliferation, differentiation and release of leukocytes in bone marrow. Over the last years, many lines of evidence have indicated that ECM proteins play crucial roles in hematopoiesis. In normal adults, myelopoiesis and partial lymphopoiesis occur in bone marrow. Cells of the medullary stroma locally produce cytokines and ECM proteins. These cells and their products spatially organized in the ECM form the hematopoietic bone marrow microenvironment (16). The production of cytokines depends on the organization of the bone marrow microenvironment determined by adequate levels of ECM proteins and cytokines (5). Based on these findings, modifications in proteins that compose bone marrow ECM may compromise the microenvironment and modify cytokine synthesis. The final result may be a change in cell production and/or differentiation in bone marrow.

In this study we demonstrated that fibronectin and laminin were expressed in both control and undernourished mice, although the undernourished group showed higher expression of these glycoproteins than the control group. This difference in expression may dramatically modify the bone marrow microenvironment, since fibronectin and laminin are central proteins involved in the regulation of hematopoietic cell proliferation and/or differentiation $(4,5)$.

Fibronectin and laminin are synthesized and deposited on the extracellular network by bone marrow stromal cells. Fibronectin is involved in the adhesion and maturation of the myeloid lineage $(17,18)$ and lymphoid precursor cells (19). More recent work has demonstrated that multipotent hematopoi-
Table 2 - Comparative profile of bone marrow protein bands in control and undernourished mice.

These data were obtained by SDS-PAGE. The bands were measured and molecular mass was determined by densitometry. Results are reported as band areas $\left(\mathrm{cm}^{2}\right)$, and albumin $(0.5-5 \mu \mathrm{g})$ was used as standard. Results are reported as concentration $(\mu \mathrm{g})$ per $45 \mu \mathrm{g}$ of protein applied to each SDS-PAGE lane. Absence of bands is indicated by the (-) symbol. Proteins of less than $30 \mathrm{kDa}$ are not shown. Control ECM indicates the ECM proteins obtained from the bone marrow of control mice. Undernourished ECM indicates the ECM proteins obtained from the bone marrow of undernourished mice.

\begin{tabular}{ccccc}
\hline $\begin{array}{l}\mathrm{MW} \\
(\mathrm{kDa})\end{array}$ & $\begin{array}{c}\text { Control ECM } \\
\left(\mathrm{cm}^{2}\right)\end{array}$ & $\begin{array}{c}\mu \mathrm{g} / 45 \\
\mu \mathrm{g} \text { protein }\end{array}$ & $\begin{array}{c}\text { Undernourished ECM } \\
\left(\mathrm{cm}^{2}\right)\end{array}$ & $\begin{array}{c}\mu \mathrm{g} / 45 \\
\mu \mathrm{g} \text { protein }\end{array}$ \\
\hline 240 & 0.12 & 0.48 & 0.61 & 2.33 \\
220 & 0.06 & 0.12 & 0.34 & 1.25 \\
182 & 0.35 & 1.28 & 0.90 & 3.54 \\
150 & 0.28 & 1.00 & 0.57 & 2.17 \\
144 & 0.38 & 1.41 & 0.34 & 1.25 \\
127 & 0.19 & 0.64 & 0.34 & 0.25 \\
123 & 0.26 & 0.93 & - & - \\
108 & 0.50 & 1.89 & 0.98 & 3.83 \\
85 & 0.14 & 0.44 & 0.12 & 0.36 \\
76 & - & - & 0.35 & 1.29 \\
72 & 0.49 & 1.85 & 0.23 & 0.87 \\
60 & - & - & 0.57 & 2.17 \\
56 & 5.01 & 20.02 & 5.55 & 22.20 \\
49 & 0.63 & 2.41 & - & - \\
46 & 0.09 & 0.24 & 0.12 & 0.36
\end{tabular}
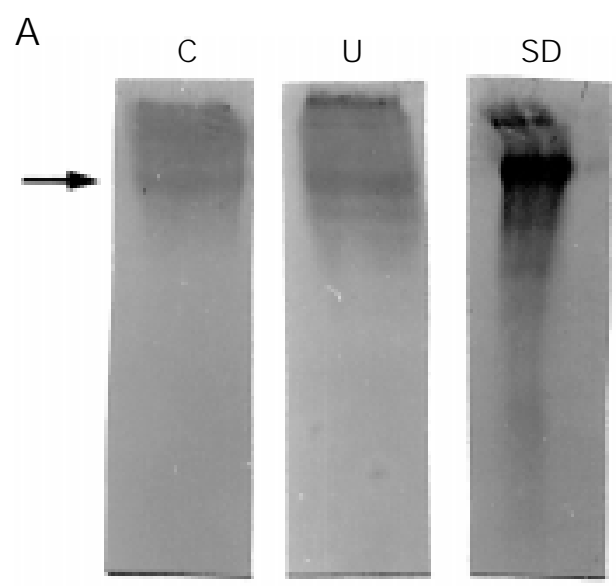

B

Figure 2 - Western blot reaction against fibronectin. Samples $(45 \mu \mathrm{g} / \mathrm{lane}$ for lanes $\mathrm{U}$ and $\mathrm{C}$ and $1.5 \mu \mathrm{g}$ of commercial fibronectin, lane SD) were separated by SDS-PAGE under reducing conditions followed by electrotransfer onto nitrocellulose membranes for immunodetection of fibronectin (A). Lane $U$ refers to samples obtained from the undernourished group, lane $C$ refers to samples obtained from the control group, and lane SD refers to commercial fibronectin run as standard. Densitometric measurement was performed (B) and the differences in band areas are shown. The solid line refers to the control sample, and the dashed line refers to the undernourished mouse sample. A similar profile was obtained in five different experiments done with the same ECM pool (control and undernourished). We tested two different groups of control and undernourished mice with similar results. 
A
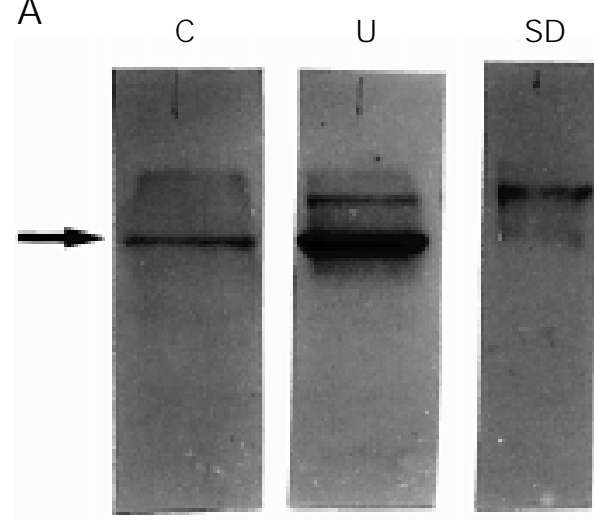

B

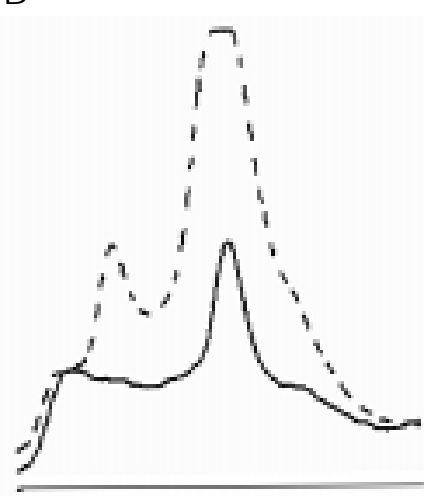

Figure 3 - Western blot reaction against laminin. These data were obtained as in the previous figure, blotting the membrane with anti-laminin antibodies (A). Lanes $\mathrm{U}$ and $\mathrm{C}$ were loaded with $45 \mu \mathrm{g}$ of protein extracted from ECM bone marrow (undernourished and control group, respectively) and lane SD was loaded with $1 \mu \mathrm{g}$ of commercial laminin, used as standard. Densitometric measurement was performed (B) and the differences in band areas are shown. The solid line refers to the control sample and the dashed line refers to the undernourished mouse sample. A similar profile was obtained in three different experiments done with the same ECM pool (control and undernourished). We tested two different groups of control and undernourished mice with similar results.

etic progenitor cells adhere to fibronectin in bone marrow (20). Bone marrow precursor cells may attach to fibronectin through $\alpha 5 \beta 1$ and/or $\alpha 4 \beta 1$ integrins or through membranebound proteoglycans $(20,21)$. It has been demonstrated that the $\alpha 4 \beta 1$ and $\alpha 5 \beta 1$ integrin receptors are differentially expressed during myeloid maturation (21). Cell adhesion to fibronectin may be an important step in the control of hematopoiesis. It has been demonstrated that the interaction of fibronectin with hematopoietic precursor cells through $\alpha 5 \beta 1$ integrin may prevent cell proliferation in the presence of hematopoietic mitogenic growth factors (22). The role of laminin in bone marrow has been less studied. However its importance for the homing of precursor cells to bone marrow has been demonstrated $(4,5)$. Modification in laminin level may alter the differentiation route of cells in bone marrow, as well as the release of differentiated hematopoietic cells from bone marrow to blood.

The correlation between malnutrition and bone marrow ECM has not been investigated. However, ECM has been studied in other tissues, such as liver and thymus, in malnutrition. Perinatal food restriction reduces the content but not the concentration of liver ECM in rats (23). A dense thymic ECM positively correlated with the degree of thymocyte depletion has been shown to occur in human malnutrition (24). The authors suggested that these effects may represent a cause-effect relationship in which the contact of thymocytes with abnormally high amounts of thymic ECM triggers and/or enhances programmed cell death.

ECM not only functions as the structural supporting element for cells and tissues but plays a major role in modulating the biology of the cell and its response to growth factors, hormones and vitamins. The composition of the matrix, however, is not static, but changes both during normal development and tissue repair and regeneration $(10,24)$. On the basis of these considerations, we suggest that protein malnutrition might be altering bone marrow ECM structure (maybe due to altered synthesis of its components), thus modifying the hematopoietic microenvironment and/or hematopoiesis. Whether malnutrition modifies other components of bone marrow ECM, such as collagens, thrombospondin and proteoglycans, is currently under investigation in our laboratory.

\section{Acknowledgments}

Prof. Dr. Vera Lucia Cardoso Tramonte (Departamento de Nutrição, UFSC) is gratefully acknowledged for permitting the use of metabolic cages and full access to the Laboratório de Nutrição Experimental. 


\section{References}

1. Fried W, Shapiro S, Barone J \& Anagnostou A (1978). Effect of protein deprivation on hematopoietic cells and on peripheral blood counts. J ournal of Laboratory and Clinical Medicine, 92: 303-400.

2. Chandra RK (1991). Nutrition and immunity: lessons from the past and new insights into future. American J ournal of Clinical Nutrition, 53: 1083-1094.

3. Keusch RL \& Farthing MJ G (1986). Nutrition and infection. Annual Review of Nutrition, 6: 131-154.

4. Mayani H, Guilbert LJ \& J anowsaWieczorek A (1992). Biology of the hematopoietic microenvironment. European J ournal of Haematology, 49: 225-233.

5. Klein $\mathrm{G}$ (1995). The extracellular matrix of the hematopoietic microenvironment. Experientia, 51: 914-926.

6. Alvarez-Silva M \& Borojevic R (1996). Granulocyte-macrophage colony-stimulating factor (GM-CSF) and interleukin-3 (IL3) activities in schistosomal liver granulomas are controlled by stroma-associated heparan sulfate proteoglycans. J ournal of Leukocyte Biology, 59: 435-441.

7. French-Constant C (1995). Alternative splicing of fibronectin - many different proteins but few different functions. Experimental Cell Research, 221: 261-271.

8. Hynes RO (1990). Fibronectins. Rich A (Editor), Springer Series in Molecular Biology. Springer Verlag, New York.

9. Yoshikawa H \& Sakihama Y (1996). Costimulation of fibronectin receptor promotes Fc gamma R-mediated rescue of IL-3-dependent bone marrow-derived cells from apoptosis. J ournal of Immunol- ogy, 156: 1832-1840.

10. Yurchenco PD \& O'Rear J (1994). Basal lamina assembly. Current Opinion in Cell Biology, 6: 674-681.

11. Borelli P, Mariano M \& Borojevic R (1995). Protein malnutrition: effect on myeloid cell production and mobilization into inflammatory reactions in mice. Nutrition Research, 15: 1477-1485.

12. Peters $C$, Budde $C L$, Breon TA, Kuper $A$ \& Kim J (1995). Ovine bone marrow extracellular matrix and soluble protein extraction: fetuin amino terminus microheterogeneity. American J ournal of the Medical Sciences, 309: 285-294.

13. Bradford MM (1977). A rapid and sensitive method for the quantitation of microgram quantities of protein utilizing the principle of protein-dye binding. Analytical Biochemistry, 72: 248-254.

14. Laemmli UK (1970). Cleavage of structural proteins during the assembly of the bacteriophage T4. Nature, 277: 680-685.

15. Gross RL \& Newberne MP (1980). Role of nutrition in immunologic function. Physiological Reviews, 60: 188-302.

16. Gordon MY (1988). Extracellular matrix of the marrow microenvironment. British J ournal of Haematology, 70: 1-4.

17. Patel VP \& Lodish HF (1984). Loss of adhesion of murine erythroleukemia cells to fibronectin during erythroid differentiation. Science, 224: 996-998.

18. Patel VP \& Lodish HF (1987). Fibronectin matrix is required for differentiation of murine erythroleukemia cells into reticulocytes. J ournal of Cell Biology, 105: 3105-3118.
19. Bernard P, Patel VP \& Lodish HF (1987). Lymphoid precursor cells adhere to two different sites on fibronectin. J ournal of Cell Biology, 105: 489-498.

20. Verfaillie CM, McCarthy JB \& McGlave PB (1991). Differentiation of primitive human multipotent hematopoietic progenitors into single lineage clonogenic progenitors is accompanied by alterations in their interaction with fibronectin. J oumal of Experimental Medicine, 174: 693-703.

21. Kerst J M, Sanders J B, Slaper-Cortenbach IC, Doorakers MC, Hooibrink B, van Oers $\mathrm{RH}$, von der Bom $\mathrm{AE} \&$ van der Schoot CE (1993). Alpha 4 beta 1 and alpha 5 beta 1 are differentially expressed during myelopoiesis and mediate the adherence of human CD34+ cells to fibronectin in an activation-dependent way. Blood, 81: 344351.

22. Sugahara $H$, Kanakura $Y$, Furitsu $T$, Ishikawama J , Hashimoto K, Kanayama $Y$ $\&$ Matsuzama $Y$ (1994). Induction of programmed cell death in human hematopoietic cell lines by fibronectin via its interaction with very late antigen 5 . J ournal of Experimental Medicine, 179: 1757-1766.

23. Reif $S$, Lu R, Tano M, Terranova V, Young C, Fisher J , Petell J \& Lebenthal E (1993). Perinatal food restriction in rats reduces the content but not concentration of liver extracellular matrix proteins. J ournal of Nutrition, 123: 811-816.

24. Lyra J SPO, Madi K, Maeda CT \& Savino W (1993). Thymic extracellular matrix in human malnutrition. J ournal of Pathology, 171: 231-236. 